\title{
Federal budget invests heavily in research, Indigenous health
}

\author{
Cite as: CMAJ 2018 March 19;190:E341-2. doi: 10.1503/cmaj.109-6678
}

Posted on cmajnews.com on Feb. 27, 2018.

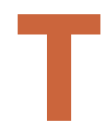

he 2018 federal budget invests close to $\$ 4$ billion in research, dedicates $\$ 1.5$ billion to improving Indigenous health, and promises to help fight the opioid crisis, end tuberculosis among the Inuit and explore options for a national pharmacare plan.

Although the appointment of Dr. Eric Hoskins, who resigned recently as Ontario's health minister, as the chair of a new advisory council on the implementation of national pharmacare generated speculation that the government would move ahead on an actual plan, the budget itself signals only the start of a "national dialogue" on drug-plan models.

"It's just not acceptable that a significant subset of the population lacks access to a pharmaceutical plan," said Finance Minister Bill Morneau. "We're going to find out how we can best approach this, so that we consider the advantages of the current system ... the employer-type approach, which does provide many people with pharmaceuticals, as well as the places where there are gaps."

In his speech to the House of Commons, Morneau highlighted the government's commitment to improving the lives of Indigenous Canadians. He also linked investing in "interdisciplinary, high-risk and fast-breaking" research with advancing Canada's long-term economic competitiveness, signalling a shift from previous governments' emphasis on applied research.

"Budget 2018 represents the singlelargest investment in investigator-led fundamental research in Canadian history," said Morneau. "Fundamental research often pushes the knowledge frontier to ultimately lay the foundation for new innovations that drive the development of new products and services for global consumers," states the budget.

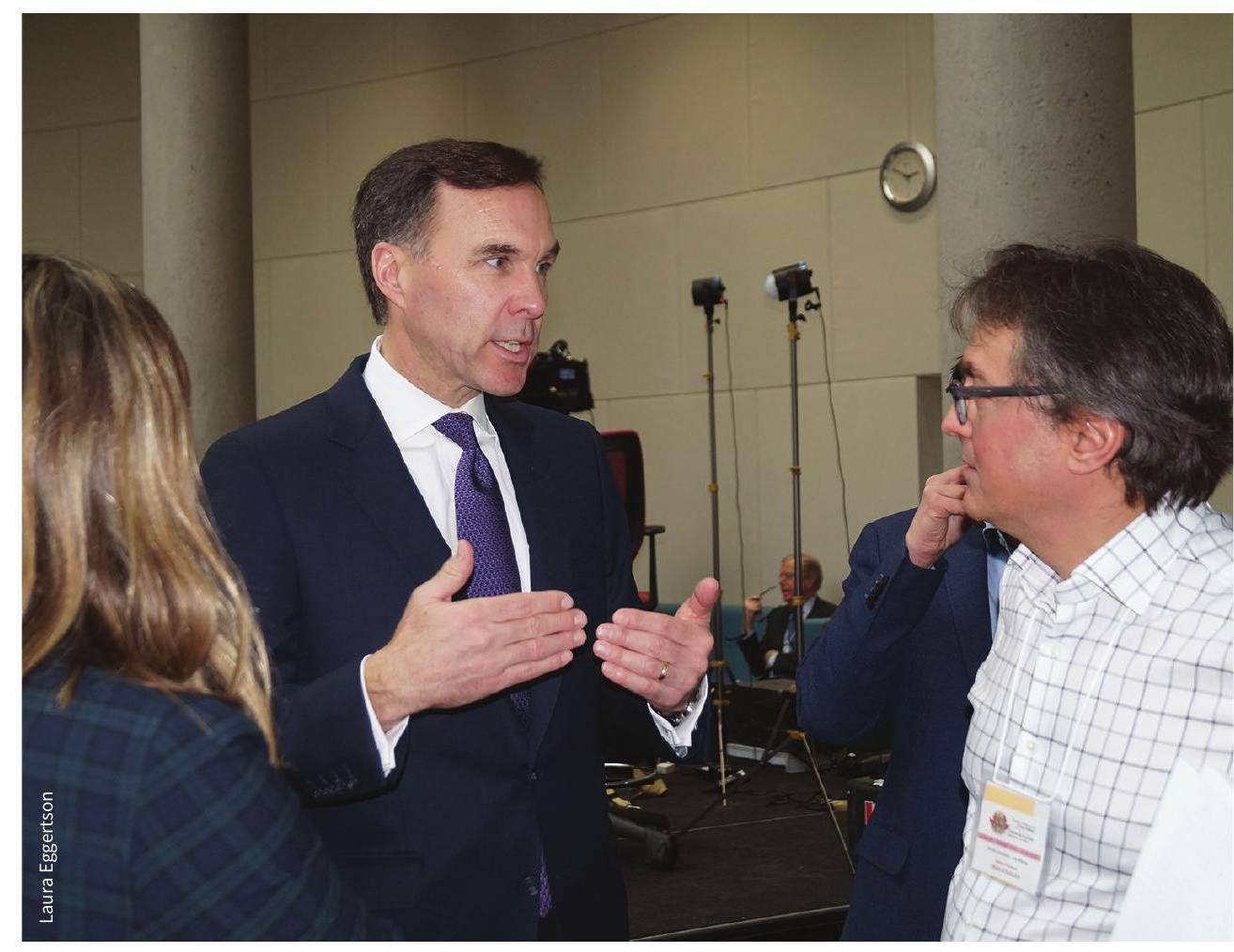

The 2018 federal budget makes the "single-largest investment in investigator-led fundamental research in Canadian history," said Finance Minister Bill Morneau.

Research investments over the next five years include:

- $\$ 925$ million to the Canadian Institutes of Health Research, Natural Sciences and Engineering Council, and Social Sciences and Humanities Research Council;

- \$275 million for a new fund to support international, interdisciplinary, fastbreaking and higher-risk research;

- \$763 million to the Canada Foundation for Innovation;

- \$540 million for a "re-imagined" National Research Council;

- $\$ 572.5$ million for a digital research infrastructure strategy;
- $\$ 210$ million to increase the number of women and early-career researchers who receive Canada Research Chairs; and

- $\$ 231.3$ million to support the indirect costs of research.

In other research investments, the Centre for Drug Research and Development will receive $\$ 48$ million to translate promising new discoveries into commercial drugs and health innovations; the Rick Hansen Institute for spinal cord injury, research and care will receive \$23.6 million; and the Council of Canadian Academies will receive $\$ 9$ million for independent scientific assessments to inform policy. 
The budget also addresses weaknesses in Canada's economic and social fabric with respect to certain groups that suffer disproportionately, such as Indigenous Canadians, said Morneau. To redress those inequities, the budget provides:

- $\$ 498$ million for medical services in 79 remote First Nations communities;

- \$490 million to the Non-Insured Health Benefits Program that covers drugs, and limited counselling and dental services, for First Nations' people;

- \$235 million to develop First Nationscontrolled health services;

- \$172.6 million to improve access to clean drinking water on reserves;

- \$200 million for culturally appropriate addiction-treatment services;

- \$109 million to "eliminate tuberculosis" in Inuit communities and finance an Inuit health survey;

- \$248.6 million for mental health and emotional supports for survivors of residential schools and their families; and

- $\$ 6$ million to develop a Métis national health strategy.
To comply with the orders of the Canadian Human Rights Tribunal, the budget also promises more than $\$ 1.4$ billion for First Nations Child and Family Services, aimed largely at preventing Indigenous children from entering foster care.

As part of the government's response to emerging health issues, the budget provides $\$ 231$ million to respond to the opioid crisis. The money includes $\$ 150$ million to provinces and territories to improve access to treatment services. Other measures include a public education campaign to reduce stigma for people with addictions; better tools to help border agents intercept fentanyl and other illegal drugs; and new treatment and prevention approaches through the Substance Use and Addictions Program.

The budget provides $\$ 62.5$ million for public education around the risks associated with using cannabis, as well as \$10 million to the Mental Health Commission of Canada to assess that risk. The Canadian Centre on Substance Use and Addiction will get a further $\$ 10$ million for research on cannabis use.

In overall spending, the budget maintains health transfers to the provinces at their previously announced levels of a 3\% increase per year, plus additional transfers for home care and mental health that will grow to $\$ 1.2$ billion by $2022-23$ under the deals Ottawa reached in bilateral negotiations with provinces and territories.

In a broad sprinkling of smaller health measures, the budget allocates $\$ 86$ million to combat gender-based violence, including "equipping health professionals to provide appropriate care to victims." Another $\$ 20$ million will support community-based dementia projects, and $\$ 75$ million will go to a pilot project in New Brunswick to better support seniors at home and in long-term care facilities. People with autism will have access to additional online resources and community-based projects to be funded with a \$20-million investment.

Laura Eggertson, Ottawa, Ont. 